\title{
TARIH BOYUNCA TRABZON HAVALISINDE KÜTÜPHANELER
}

Dündar ALIKKILIÇ ${ }^{*}$

Evrensel kültürün en önemli kısmını oluşturan kitaplar, dün olduğu gibi bugün de ulusal kültürlerin temelini teşkil eden en önemli kaynaklardır. Bilgi birikiminin gelecek kuşaklara ulaşması için yazılan kitaplar, kütüphaneler sayesinde bizlere ulaşmakta ve bugün karşımıza değeri takdir edilemeyen birer hazine olarak çıkmaktadır. $\mathrm{Bu}$ değerli hazinelerin açılıp okunması, yerlerinin bilinmesi ve gelecek nesillere aktarılması, bu kitapların yazılması kadar önemlidir. Bu maksatla, bu çalışmada Trabzon'da bulunan kütüphaneler hakkında bilgi verilecektir.

Trabzon, Doğu Karadeniz Bölgesinin en eski kentlerinden birisi ve Anadolu'da Karadeniz Kapadokya'sının meşhur bir başşehridir. ${ }^{1}$ Tarih boyunca önemli bir liman, tarım, ticaret ve sanat merkezi olmuş ve bu önemini daima muhafaza etmiş bir şehirdir. Bundan dolayı, Trabzon ve çevresinde Türk hakimiyetinden önce pek çok eser meydana getirilmiştir. Şehirdeki kültürel miras, Osmanlıların fethinden sonra daha da gelişmiş ve şehir Türk-İslâm yapıları ile süslenmiştir. Ne yazık ki bu eserlerin büyük bir kısmı günümüze kadar korunamamış, yıkılıp yok olmuştur.

Anadolu'nun bir parçası olmakla beraber, yüksek dağlarla yayladan ayrıldığı için, ayrı bir coğrafi muhit teşkil eden, denizden gelen tehditlere daima açık bulunan Trabzon havalisi, zaman zaman istilâlara uğramıştır. ${ }^{2}$ Bu istilâların Trabzon şehrinin kültürel mirası üzerinde çok yıpratıcı etkileri olmuştur. Nitekim, Trabzon'u ziyaret eden seyyahlar, şehrin bu özellikleri hakkında bilgiler vermişlerdir. Evliya Çelebi, Trabzon'un tarihî ve kültürel mirasını zikrettikten sonra, "beşinci iklimde bulunmakla su ve havasının güzelliğinden bütün halkı eğlence ve gezinti ehlidir"3 ${ }^{3}$ şeklinde bir ifadeyle Trabzon'daki incelikten, insanların sanat ve estetik anlayışının güzelliğinden bahseder. ${ }^{1869}$ 'da Trabzon'u ziyaret eden Fransız seyyahı Theophile Deyrolle Trabzon'u; "Trabzon, deniz kenarında anfiteatr şeklinde kurulmuştur. Denizden görünüşü çok güzeldir. Deniz kenarında parlak renkleri ile pitoresk (resim konusu olmaya elverişli, güzel görünüşlï) evler sıralanır. Arkalarında portakal ve

1 P. Minas Bıjişkyan, Karadeniz, Kıyıları Tarih ve Coğrafyası, (Çeviri: Hrand D. Andreasyan), İstanbul 1969, s. 42.

2 Bilâl Aziz Yanıkoğlu, Trabzon ve Havalisinde Toplanmış Folklor Malzemesi, İstanbul 1943, s. 25.

3 Evliya Çelebi, Seyahatnâme, II, İstanbul 1315, s. 457. 
zeytin ağaçları arasında yarı saklanmış diğer yapılar görünür. Yer yer, yeşillikler arasında zarif mermer sütunlara benzeyen minareler yükselir. Gülen ve iç açan bu tablo ile eski Trabzon kalesi harabelerinin haşin çizgisi bir tezat vücuda getirir." ${ }^{4}$ şeklinde tarif etmektedir.

Trabzon şehri Karadeniz Bölgesinin eğitim ve öğretim yönünden de en gelişmiş ilidir. Osmanlıların son döneminde Trabzon'da eğitim kuruluşu olarak sekiz adet medrese, eğitim süresi dört yıl olan beş adet ilkokul, bir sanat yurdu, bir askerî rüştiye, bir idâdî ve bir Darü'l-Muallimîn vardı. Aynı tarihlerde İmaret'te ve Ortahisar'da iki adet de kütüphane bulunmaktaydı. ${ }^{5}$

Tarih boyunca çeşitli milletlere ve medeniyetlere ev sahipliği yapan Trabzon'da, hiç kuşku yok ki kültürel mirasın saklanması ve kitapların muhafazası için pek çok sayıda kütüphane vücuda getirilmiştir. Fakat bu kütüphanelerin hepsi günümüze kadar ulaşmamıştır. Bununla birlikte tarihte varolup, kayıtlara geçen ve hâlâ varlığını devam ettiren kütüphanelerimiz de mevcuttur. Bunları şu şekilde belirtmek mümkündür.

\section{Sumela Manastırı Kütüphanesi}

Trabzon'un tarih sahnesindeki bilinen ilk kütüphanesi Maçka'daki Sumela (Meryemana) Manastırı Kütüphanesi'dir. İmparator Konstantin döneminde (M.S. 325-364), imparator tarafından Sümela Manastırına pek çok el yazması kitap hediye edilmiştir. İstanbul, Batı Roma İmparatorluğundan ayrıldıktan sonra Bizans İmparatoru Justinianus (527-568), hem Trabzon'un tahkim edilmesini, hem de bu manastırın genişletilmesini emrederek, buraya zengin bir kitaplık bağışlamış, ceylan derisi üzerine yazılmış değerli kitaplar hediye ettiği kaynaklarda yazılmaktadır. Justinianus kiliseye el yazmalı kitaplar dışında keşişlerin eşyalarını saklamaları için bir de gümüşten sandık hediye etmişti. 640 Yılında Bizanslı çapulcular, hem manastırı yağma etmişler hem de bu kitaplığı yakmışlardı. İstanbul'un 1204 yılında Haçlılar tarafından işgalinden sonra Trabzon'a kaçan ve "Komnenler" (Komnenos) İmparatorluğunu kuran Alexios Komnenos'un oğlu ve torunları, Sumela Manastırını genişletme ve onarma yarışına girdiler. Nitekim, Alexsios III, tacını Sumela'da giymek için bütün saray halkını manastıra götürmüş ve imparator olduktan sonra da bugünkü manastırı 72 oda ve büyük bir kitaplık ile yeniden yaptırmıştı. ${ }^{7}$ III. Alexios'un dedesi II. İonnes zamanında (1280-1285) Sumela kilisesinin dini bir merkez haline getirilmesine başlanmış olmasına rağmen III. Alexios Komnenos bu tesisin en eski kurucusu sayılır. III. Alexios'un Sumela'ya özel bir ilgi gösterdiği, çıkardığı fermanlarla bu tesisin varlığını sağlam esaslara bağladığı, kaynaklarda belirtilmektedir.

\footnotetext{
Theophile Deyrolle, 1869'da Trabzon'dan Erzurum'a (Çeviri: R. Ekrem Koçu), ?, s. 10.

Trabzon Yıllı̆̆ 97, Ankara 1997, s. 18.

Özkan Tüfek, Sumela, İstanbul 1978, s. 80.

Tarihi ve Turistik Değerleriyle Trabzon, Trabzon Turizm Müdürlüğü Yayınları No: 4, s. 178.
} 
Sumela Manastırı kütüphanesinin kurulmasından sonra buraya pek çok değerli kitaplar hediye edilmiştir. Alexios III'ün Trabzon'daki imparatorluğu sırasında (1349-1390) manastırın durumu değişmiş, buraya 17 adet el yazması kitap hediye etmiştir. ${ }^{8}$

Ünlü Alman tarihçisi J. P. Fallmerayer (1790-1861), 1840 yılında Trabzon'a yaptığı bir seyahati sırasında Sumela'yı ziyaret ederek, çeşitli bilgiler vermiştir. Fallmerayer'in burada kaldığı günlerde, kitaplar 1şıksız bir mağarada toplanmış bulunuyordu. Alman tarihçi, bir dayama merdivenle içine girilebilen bu mağaramsı kütüphanede fazla önemli bir şey bulamadığını, ekseriyetle Avrupa baskılı kitaplar gördüğünü yazmaktadır. ${ }^{9} 1860$ Yılına doğru bir takım misafir odaları ile beraber kütüphane olarak kullanılan bir salon da inşa edilmiştir. Kütüphane bölümü, giriş kapısından sonra içeriye inen merdivenlerin sonunda sağda yer alır. Ön duvarı tamamen yıkıldığından, iç duvarında duvara gayet süslü iri harflerle yazılmış "Bibliotheka" (kütüphane) kelimesi avludan görülür. ${ }^{10}$

Trabzon ve havalisi Türk idaresine geçtikten sonra Osmanlı Sultanları, birçok manastırda olduğu gibi, Sumela manastırının da eski hak ve hukukunu dikkatle korumuşlar, hatta buraya imtiyazlar vermişler, bazı hediyeler yollamışlardı. Nitekim Trabzon fatihi Fatih Sultan Mehmed'in manastırın haklarını tanıdığını bildiren bir fermanın muhafaza edildiği, kaynaklardan anlaşılmaktadır. Bununla birlikte, Sumela'da bulunan iki şamdan Yavuz Sultan Selim (1512-1520)'in hediyesi olarak biliniyordu. Bundan sonra Çaldıran savaşını da kazanan Selim, manastıra kıymetli eşyalarla birlikte 10 adet el yazma kitap hediye etmiştir. ${ }^{11}$ Burada ayrıca Ayrıca, Sultan II. Beyazid, I. Selim, II. Selim, IV. Murad, Sultan İbrahim, IV. Mehmed, II. Süleyman, II. Mustafa ve III. Ahmed tarafından gönderilmiş fermanlar bulunduğu bildirilmektedir. XVIII. Yüzyılın ikinci yarısından itibaren manastır ile Eflak Voyvodalarının ilgilendikleri ve devamlı yardımlar ve yazılar gönderdikleri tespit olunmuştur. Ghikos (1775), Stephan (1764), Hypsilantes (1775) gibi Voyvodaların Sumela ile ilgilendikleri kaynaklardan anlaşılmaktadır. Bu konuda 1775 tarihli bir belge Atina Bizans Müzesinde bulunmaktadır. Tabiatıyla, manastır arşivinde, bütün Osmanlı dönemi boyunca İstanbul patriklerinin yolladıkları yazılar da muhafaza ediliyordu. ${ }^{12}$

Daha sonraları, Papadopoulos-Kerameus buradaki yazmaların bir kataloğunu yapmış, diğer araştırmacılar da buna birkaç yazma adı daha ilave etmiştir. Sayıları 85-90 kadar olan bu el yazmalar, manastır boşaldıktan sonra dağılmıştır. Bunlardan bir tanesi şimdi Atina Bizans Müzesi'nde; büyük bir kısmı ise Ankara'da bulunmaktadır. Diğer taraftan bu manastıra ait bazı vesika ve yazılar, piyasaya

Mustafa Uzunlar, Trabzon Yakınlarında Sumela Manastırı (Basılmamış Bitirme Tezi), Erzurum 1991, s. 11. Semavi Eyice, "Trabzon Yakınında Meryemana Manastırı", Belleten c. XXX, Ankara 1966, s. 257.

Özkan Tüfek, a. g. e., s. 90.

Tüfek, a. g. e., s. 83.

Uzunlar, a. g. e., s. 12. 


\section{-308- D. Alikalic: Tarih Boyunca Trabzon Havalisinde Kütüphaneler}

dağılmış, bir kısmı da Yunanistan'a götürülmüştür. Ankara'da muhafaza edilen yazmaların ekseriyeti 17. yüzyıldan sonraya aittir. Yalnız bunlar arasında, 11 ve 12. yüzyıllara ait olarak tarihlendirilen üç ayrı, Dört İncil (Tetraevangelium) bulunuyordu. Bunların tezhipli ve minyatürlü oldukları anlaşılmakta ise de, hayli harap bir halde idiler. Çoğu 17-18. yüzyıllara ait dini kitapların arasında 2 adet Aziz Barnabas ve Sophronios'un Akuluthia'larına rastlanır. Profan konulu iki yazmadan biri, Manuel Malaxos tarafından 16. yüzyılın sonunda yazılan Bizans İmparatorları ve Osmanlı Sultanları Kronografyası; diğeri 1691'de Stephonas oğlu Khristophoros'un tertiplediği, Sinop şehri Hıristiyan ahalisinin listesidir. Ankara'daki yazmalar arasında ayrıca 18 ve 19. yüzyıllara ait manastırın mektup, protokol ve masraf defterleri de tespit olunmuştur. Muhakkak ki piyasada ve hususi ellerde bazı vesikalar ve kitaplar vardır. Nitekim 1956 yılında İstanbul'da bazı sahaflarda Sumela Manastırı Kütüphanesi'ne ait mührü taşıyan bazı evrakların satıldığı Eyice'nin kayıtlarından anlaşılmaktadır. İçinde değerli minyatürler olan Dört İncil nüshasının ise İstanbul Arkeoloji Müzesi'ne intikal ettiği bilinmektedir. Kütüphaneyle ilgili bazı vesikalar, şimdi Atina'da bulunduğu gibi, Sumela Manastırı menşeli iki kilise eşyası da Atina'da Benaki Müzesi'nde bulunmaktadır. ${ }^{13}$

1923'te Rumların Yunanistan'a gönderilmesi sırasında keşişler en değerli eşyalarını St. Barbara Kilisesine gömerek diğer Rumlar gibi göç etmişlerdi. Tarsicio Succi adlı İtalyan papazın belirttiğine göre; Türk hükümetinden izin alan Amprosios adlı keşiş 25 Kasım 1931'de St. Barbara'ya gelerek Sumela'ya ait olan bu kıymetli eşya ve eserlerin bir kısmını Yunanistan'a götürmüştür. Bugün bu eşyalar, Atina'daki Bizans Müzesi'nde sergilenmekte ve "Türkiye'deki Bizans Eserleri" adlı periyodikte sürekli olarak aleyhimizde bir propaganda kanıtı olarak Meryemana Manastırının bugünkü durumu yayınlanmaktadır. ${ }^{14}$

\section{Kuştul Manastırı Kütüphanesi}

Sumela Manastırı kütüphanesinden sonra bilinen en eski kütüphane, hakkında çok az bilgi olan Kuştul Manastırı Kütüphanesi'dir. Kuştul Manastırı Maçka'daki manastırların en güzeli diye bilinir. Şimdi harap bir haldedir. Rivayetlere göre Ortodoks aleminin teoloji/ilahiyat fakültesi olarak hizmet vermiştir. Bu manastır da Sumela Manastırı gibi yüksek ve 1 ssız bir tepede yapılmıştır. Sumela'dan farkı, Sumela Manastırı, kayanın kovuğunda yapılmışken bu manastır kayanın tepesine inşa edilmiştir. Sumela'da olduğu gibi bu yapının kütüphanesinde de değerli el yazma kitaplar vardı. Bugün ise İstanbul Ayasofya Müzesi'nde Sumela Manastırı hazineleri ile birlikte saklandıkları bilinmektedir. $^{15}$

Eyice, a. g. e., s. 258.

Uzunlar, a. g. e., s. 27.

Uzunlar, a. g. e., s. 37. 


\section{Hatuniye Kütüphanesi}

Osmanlıların Trabzon'u fethiyle şehirde giriştikleri yapılanma içinde ilk kaydı olan kütüphane, Yavuz Sultan Selim'in annesi Ayşe Gülbahar Hatun adına 1514 yılında Zağanos Köprüsü'nün yakınındaki bir külliye içerisinde yapılmıştır. Külliyeden cami ile türbe günümüze gelebilmiş; imaret, medrese, hamam, kütüphane ve mektep yıkılmış, yerine Gülbahar Hatun İlkokulu yapılmıştır. ${ }^{16} 1553$ y1lına ait bir Tahrir Defterinde, Hatuniye ya da Gülbahar Camii'nin bulunduğu yerde (külliyede) bir medrese, kütüphane ve türbenin bulunduğu kayıtlıdır. ${ }^{17}$ Yavuz Sultan Selim, tesis edilen bu külliyeye büyük vakıflar tahsis ederek hizmetlerini sürdürmesini sağlamıştır. ${ }^{18}$ Hatuniye külliyesindeki bu kütüphane tahrip olduğundan daha sonra Trabzon valisi Hazinedâr-zâde Osman Paşa tarafından yeni bir kütüphane inşa edilmiş ve açılışı kardeşi Abdullah Paşa tarafından yapılmıştır. Gülbahar Hatun Mahallesinde bulunan ve 1860 tarihinde açılmış olan kütüphanede 444 kitap bulunmaktaydı. ${ }^{19}$

\section{Fatih Ortahisar Camii Kütüphanesi}

Trabzon'daki diğer bir kütüphane Fatih-Ortahisar Camii Kütüphanesi'dir. Burada daha önce Roma İmparatoru Konstantin'in yeğeni Hanmibalianos tarafından yaptırılmış eski bir Roma tapınağı vardı. 1461 Tarihinde Türklerin Trabzon'u ele geçirmesinden sonra bu kilise, Fatih Camii adı verilerek camiye çevrilmiş, Fatih Sultan Mehmed şehrin fethinden sonraki ilk Cuma namazını burada kılmıştır. Ortahisar Fatih Camii'nde değişik zamanlarda nakışla süslemeler yapılmış ve kitabeler konulmuştur. Mihrabın doğusundaki oda 1842 yılında kütüphane haline getirilmiş ve kapısı üzerine bir kitabe yerleştirilmiştir. ${ }^{20} \mathrm{Bu}$ kitabeye göre, kütüphane, 1842 senesinde Trabzon Valisi Hazinedâr-zâde Abdullah Paşa'nın kardeşi Ahmed Muhtar Bey tarafından kurulmuştur. Buradaki kitapların, 19161917'deki Rus istilası sırasında Ruslar tarafından götürüldüğü söylenmektedir. ${ }^{21}$ Başbakanlık Devlet Arşivleri Genel Müdürlüğü Osmanlı Arşivi’nde bulunan bir vesika buranın umumi bir kütüphane olarak kullanıldığını göstermektedir. 1860 tarihli bir belgede "Trabzon eyaletinde arazi ve diğer hususlara ait defter, senet ve evrakların Fatih Camii Kütüphanesine konulduğu"22 belirtilmektedir.

Tarihi ve Turistik Değerleriyle Trabzon, s. 22.

Heath W. Lowry, Trabzon Şehrinin İslâmlaşma ve Türkleşmesi, İstanbul 1981, s. 68.

Trabzon Yıllı̆̆ ' '97, Ankara 1997, s. 64. BOA. İbnül Emin Tasnifi, Evkaf 1866, 4973, 6318, 6583.

Veysel Usta-Yaşar Soytürk, Tarihi, Coğrafyası, Folkloru ile İlimiz Trabzon, ?, s. 81.

Tarihi ve Turistik Değerleriyle Trabzon, s. 14.

Ömer Akbulut, Trabzon Kitabeleri, İstanbul 1953, s. 9.

BOA.(Başbakanlık Osmanlı Arşivi) Bâb-ı Âli Evrak Odası Sadaret Evrakı Mektubi Kalemi, Umum Vilâyât Kısmı Dosya No: 444, gömlek no: 56. 


\section{-310- D. Alikalıc: Tarih Bovunca Trabzon Havalisinde Kütüphaneler}

\section{Ortahisar-Saraç-zâde Kütüphanesi}

Trabzon kütüphaneleri içerisinde en çok tamir gören ve en çok kitaba sahip olanı Saraç-zâde Kütüphanesi olarak bilinen Ortahisar Kütüphanesi'dir. Bu kütüphane, Ortahisar Camiinin karşısında bulunan mescidin ikinci katında olup, Saraç-zâde Mustafa Efendi tarafından 1762'de yaptırılmıştır. Zağanos mahallesinde çıkan bir yangının buraya kadar sıçraması sonucu yanmış olan kütüphane, padişahın göndermiş olduğu parayla Vali Rüstem Paşa tarafından onarılmıştır. Aradan bir süre daha geçtikten sonra bu kütüphane tekrar onarım görmek durumunda kalmıştır. Trabzonlu şair Hafız Zühtü tarafından yazılmış olan onarım kitabesinde; kütüphanenin yangın geçirdiği, iki kez onarım gördüğü kaydedilmektedir. Son iki mısrada ebcet hesabıyla düşülen tarih, tamiratın 1866 tarihinde yapılmış olduğunu göstermektedir. 611 Kitabı mevcut olan kütüphanenin kitapları, Cumhuriyetin ilanından sonra, şehirde kurulan Trabzon İl Halk Kütüphanesine devredilmiştir. ${ }^{23}$ Değerli sanat tarihçisi Haşim Karpuz, Trabzon'daki Türk devri yapılarından bahsederken, Fatih Medresesi'nin devamı sayılabilecek Saraç-zâde Medresesinin (Pir Efendi) mescid kısmı ile birkaç odasının günümüze kadar geldiğini, Yıldız Sarayı Albümündeki resme göre medrese avlusunun ortasında büyük bir şadırvan olduğunu ve 1866 tarihli kitabesine göre bir de kütüphanesi bulunduğunu ${ }^{24}$ zikretmektedir.

\section{Fetvahane Kütüphanesi}

Trabzon'daki bir başka kütüphane de Fetvahane Kütüphanesi'dir. Bânisi, Trabzon valilerinden Hazinedâr-zâde Osman Paşa'dır. Hazinedâr-zâde Osman Paşa, valiliği sırasında (1827-1842), Ortahisar Camiini tamir ettirmiş, içerisine bir fetvahane ve bir kütüphane kurdurmuştur. ${ }^{25}$ Bir başka kaynakta da 1842 yılında Ortahisar fetvahanesinde açılan kütüphaneden bahsedilmektedir. Ortahisar mahallesinde bulunan kütüphanenin 451 kitabı mevcuttu. ${ }^{26}$

Birinci Dünya Savaşı'ndan az önce Hatuniye Kütüphanesi'nin kitapları Fetvahane Kütüphanesi'ne kaldırılmış ve böylece oradaki kitap sayısı 895'e ulaşmıştır. Rusların Trabzon'u işgali sırasında şehre gelen Rus Arkeolog Prof. Ouspenski buradaki kitaplardan 497'sini seçerek sandıklara doldurmak suretiyle Rusya'ya göndermiştir. Cumhuriyetin ilanından sonra bu kütüphanelerde bulunan kitaplar, Memleket Kütüphanesi'ne devredilmiş olup, bunlardan bir kısmı halen Trabzon İl Halk Kütüphanesi Koleksiyonu'nda bulunmaktadır. ${ }^{27}$

\footnotetext{
Usta-Soytürk, a. g. e., s. 80.

Haşim Karpuz, "Trabzon'da Yok Olan Bazı Türk Devri Yapıları" Vakıflar Dergisi, c. XXIII, Ankara 1994, s. 146-147.

25 Naci Yüngül, "Trabzon'daki Hazinedâr-zâde Abdullah Paşa Çeşmesi", Vakıflar Dergisi, c. XIX, Ankara 1985, s. 261.

26 Cumhur Odabaşoğlu, Trabzon 1869-1933 Yılları Yaşantısı, ? s. 174.

27 Usta-Soytürk, a. g. e., s. 81.
} 


\section{Hacl Ahmed Efendi Kütüphanesi}

Trabzon yöresinde kurulan kütüphanelerin en faal olanlarından birisi de Of'un Uğurlu (Çifaruksa) beldesinde, Gümüşhaneli Hacı Ahmed Ziyaüddin Efendi tarafından 1866 tarihinde kendi adına kurmuş olduğu "Hacı Ahmed Efendi Kütüphanesi"dir. ${ }^{28} 1898$ Maarif Salnamesine göre: Trabzon'daki üç kütüphanede 1500 kitap, Of'ta bulunan Hacı Ahmed Efendi Kütüphanesi'nde 800 kitap bulunmaktaydı. Haşim Albayrak tarfından yazılan bir eserde, Of'taki Hacı Ahmed Efendi Kütüphanesini kuran Gümüşhaneli Ahmed Ziyaüddin Efendi'nin, İstanbul'da Avârız Sandığı şeklinde bir yardımlaşma vakfı kurarak büyükçe bir matbaa yaptırdığı, bu matbaadan gönderdiği kitaplar ve vakıftan tahsis ettiği 500'er altın ile Of, İstanbul, Rize ve Bayburt'a kurmuş olduğu kütüphanelere 18.000 cilt kitap gönderdiği belirtilmektedir. ${ }^{29}$

\section{Eski Kütüphane}

Of'taki diğer bir kütüphane, Uğurlu Beldesi, Merkez Mahallesindeki Eski Kütüphane'dir. 1867 yılında yapılmış olan kütüphane kesme taştan inşa edilmiş, kare mekanlı, tek katlı bir yapıdır. ${ }^{30}$ Bu kütüphanede ne kadar kitap olduğu hakkında bir bilgi yoktur.

\section{Hacı Salih Efendi Kütüphanesi}

Çaykara'nın Karaçam Beldesi'nde (Ogeni ûlâ=Yukarı Ogene) ilk Of müftülerinden Hacı Salih Efendi (1793-1888) kütüphanesi mevcuttur. Bugün dördüncü kuşak torunları elinde, Çaykara'da kendi yaptırdığı misafirhanede bulunan kütüphanede, yaklaşık olarak 1000 cilt kitap mevcuttur. Bu kütüphane, Trabzon ve havalisindeki bilinen en zengin tarihî kütüphanedir. Hacı Salih Efendi, Erzurum Yakutiye Medresesi'nden 1826 yılında icazet alıp Of havalisinde ilim irşadıyla meşgul olmuştur. 1826'de Mezun-u bil'iftah ve 1828 'de Şeyh-ül İslâm Ömer Hulusi Efendi'nin takririyle Of müftülügüne (kadılığına) atanmıştır. Of'ta Rumca konuşmayı ilk olarak Hacı Salih Efendi yasaklamış ve Türkçe konuşmayı teşvik etmiştir. Of'a çeşitli meyve ağaçları getirtip, meyve ağacı diktirmiş ve ilk kez ağaçlandırma faaliyetlerini yürütmüş, bu çalışmaları desteklemiş münevver bir kişi idi. ${ }^{31}$

Bu kütüphanedeki kitapların pek çoğu yazma eser olup, bir kısmı Hacı Salih Efendi'nin kendisi tarafından istinsah edilmiş, bir kısmı da mezun olduğu Yakutiye Medresesi'nden getirilmiştir. Hocalarına ve medrese kütüphanesine ait önemli nadide yazma eserlerle birlikte kendi kaleme aldığı risalelerle çok zengin bir kütüphane oluşturmuştur. Bu güzide eserlerin yanında Of ve havalisinde

Tarihi ve Turistik Değerleriyle Trabzon, s. 34.

Haşim Albayrak, Of ve Çaykara, Ankara 1954, c. 1, s. 68.

Reşat Sümerkan-İbrahim Okman, Kültür Varlıklarlyla Trabzon, ?, s. 211.

Bu bilgiler dördüncü kuşak torunu olan ve şimdi Atatürk Üniversitesi İlahiyat Fakültesinde Öğretim Üyesi olan Doç. Dr. Nasrullah Hacımüftüoğlu'ndan alınmıştır. 


\section{-312- D. Alikulic: Tarih Boyunca Trabzon Havalisinde Kütüphaneler}

verdiği fetvaların suretlerini de muhafaza etmiş, gelecek kuşaklara zengin bir arşiv bırakmıştır. Bugün bu kitaplık ve arşiv vesikaları torunlarından Nasrullah Hacımüftüoğlu tarafından muhafaza edilmektedir. ${ }^{32}$

Aynı şekilde Of ve Çaykara havalisinde sayıları elliyi aşan irili ufaklı medreseler düşünülürse bu havalide ilmin yaygınlığı ve kitapların çokluğundan rahatlıkla söz edilebilir. Hacı Salih Efendi kütüphanesine benzer bir kitaplığın da Düzköy ilçesi müderrislerinden Hüseyin Efendi'ye ait bir kitaplık olduğu bilinmekle beraber muhtevası hakkında fazla bilgi yoktur.

Sosyal ve Kültürel yönden önemli bir konumda bulunan Trabzon ve havalisinde bahsedildiği üzere pek çok kütüphane bulunmaktadır. Bunlardan Cumhuriyet dönemi öncesine ait kütüphanelerin bazıları şunlardır; Hatuniye, Ortahisar, Saraç-zâde, Fetvahane, Müdafa-i Hukuk Cemiyeti Kütüphanesi, Trabzon Muallimler Cemiyeti Kütüphanesi, Trabzon Türk Ocağı Kütüphanesi ve Trabzon Halkevi Kütüphanesi.

\section{Cumhuriyet Döneminde Kurulan Kütüphaneler}

Cumhuriyetten sonra, 1979'da Trabzon, Of ve Akçaabat'ta toplam 8 kütüphane vardı. Of Halk Kitaplığındaki kitap sayısı 1979'da 2103 adet olup, yöresel kaynakların çok az olması dikkati çekmektedir. ${ }^{33} 1981$ Yılında Sürmene'de açılan 100.Y1l Kütüphanesi pek çeşitlilik arz etmeyip neredeyse öğrencilerin ödev yapma salonu şeklini almıştır. Trabzon'daki İl Halk Kütüphanesi, Cumhuriyet'ten sonra Necmati Spor Kulübü tarafından kullanılmakta iken, 1927 yılında 1500 lira karşılığında yalnızca kütüphane binası olarak kullanılmak üzere keşfi yapılmış, Meclis-i Umum-i Vilayetçe de uygun görülmüş, bunu müteakip, 1 Ekim 1927 tarihinde hizmete açılmıştır. Uzun yıllar burada hizmet verilmiş olmakla birlikte, şehrin sosyo-ekonomik gelişmesi ve okulların çoğalması nedeniyle kütüphane binası ihtiyaca cevap veremez hale gelmiştir. Bunun üzerine Milli Eğitim Bakanlığı'nca Atapark'ta 400.000 liraya yeni bir bina yaptırılmıştır. 19 Mayıs 1966 tarihinden itibaren kütüphanecilik hizmetleri bu binada verilmektedir. Halen 500 civarında el yazması, 3000 civarında Arap harfli basma eser ve 40.000 civarında yeni harfli kitabıyla yılda yaklaşık 150.000 okuyucuya hizmet vermektedir.

Şehirdeki ikinci kütüphane binası ise, 1957 yılında İl Özel İdaresi tarafından yaptırılarak Uzun Sokak No: 90'da hizmete açılmıştır. Halen çocuk kütüphanesi olarak hizmet veren bu kütüphane 5500 kitap mevcuduyla yılda yaklaşık 20.000 okuyucuya hizmet vermektedir. ${ }^{34}$ Ayrıca Trabzon'da

Bu kitapların ve belgelerin bir kısmı tarafımızdan görülmüştür.

Haşim Albayrak, a. g. e., s. 68.

Usta-Soytürk, a. g. e., s. 81. 
K.T.Ü.'inde bulunan ve daha ziyade akademik çevrelerce kullanılan modern ve gelişmiş bir kütüphane de bulunmaktadır.

Tarih boyunca önemli bir kültür merkezi konumunda olan Trabzon'un, bu konumunu korumasında kütüphanelerinin önemli bir rolü olduğunu söyleyebiliriz. Kütüphanelerimizi korumay1, geliştirmeyi ve bunun için imkanlarımız ölçüsünde, her türlü katkıyı sağlamayı bir yurttaşlık görevi bilmeliyiz. Ama şunu da bilmeliyiz ki, iyi bir yurttaş ve insan olmamız, sadece kütüphaneleri korumak ve geliştirmekle değil, bir okuyucu olarak kütüphanelerimizi kullanmakla mümkün olacaktır. 